\title{
PENGEMBANGAN DAN VALIDASI METODE KROMATOGRAFI LAPIS TIPIS DENSITOMETRI UNTUK PENETAPAN KADAR TEOFILIN DAN EFEDRIN HIDROKLORIDA SECARA SIMULTAN PADA SEDIAAN TABLET
}

\author{
DEVELOPMENT AND METHOD VALIDATION DENSITOMETRY THIN LAYER \\ CHROMATOGRAPHY FOR THESIMULTANEOUS DETERMINATION OF THEOPHYLLINE \\ AND EPHEDRINEHYDROCHLORIDE IN TABLET \\ DOSAGE FORM
}

\section{Lestyo Wulandari, Yuni Retnaningtyas, Diyanul Mustafidah}

Fakultas Farmasi Universitas Jember

Jl. Kalimantan I No.2, Kampus Tegal Boto Jember 68121

Email : lestyo@yahoo.com

Diterima : 7 Januari 2013, Direvisi : 17 Januari 2013, Disetujui : 4 Februari 2013

\begin{abstract}
ABSTRAK
Kombinasi Teofilin dan Efedrin sering digunakan untuk menimbulkan efek aditif dalam meringankan gejala gangguan saluran pernapasan. Penelitian ini bertujuan untuk mengembangkan suatu metode Kromatografi Lapis Tipis (KLT) Densitometri untuk penetapan kadar Teofilin dan Efedrin hidroklorida pada sediaan tablet. Metode ini menggunakan lempeng KLT silika gel 60 F254 sebagai fase diam, dan campuran Etilasetat : Asam asetat glasial : Aquabides (11: $5: 1 \mathrm{v} / \mathrm{v} / \mathrm{v}) \mathrm{s}$ ebagai fase gerak. Untuk mendeteksi Efedrin hidroklorida, lempeng KLT dielusi kembali dengan $0.5 \%$ larutan ninhidrin dalam aquabidest dan dipanaskan dalam oven selama 15 menit. Evaluasi secara kuantitatif menggunakan scanner Densitometer win CATS Camag dengan detektor UV-Vis pada $\lambda 279 \mathrm{~nm}$ untuk Efedrin hidroklorida dan $505 \mathrm{~nm}$ untuk Teofilin. Hasil validasi menunjukkan bahwa metode ini memberikan hasil analisis yang selektif dan spesifik, linier, presisi dan akurat. Metode KLT Densitometri ini dapat diterapkan untuk menetapkan kadar Teofilin dan Efedrin hidroklorida secara simultan pada sediaan tablet dengan cepat, sederhana dan selektif.
\end{abstract}

Kata kunci : KLT Densitometri, validasi, Teofilin, Efedrin hidroklorida

\section{ABSTRACT}

The combination of Theophylline and Ephedrine is often used to induce an additive effect in alleviating the symptoms of respiratory disorders. This research is aimed to develop a Thin Layer Chromatography (TLC) densitometry methodfor the simultaneous determination of Theophylline and Ephedrine hydrochloride in tablet dosage form. The method employed TLC aluminium plates precoated with silica gel 60 F254 as the stationary phase and the mixture of ethyl acetate : glacial acetic acid : aquabidest $(11: 5: 1 \mathrm{v} / \mathrm{v})$ asthe eluen system. For detection of Ephedrine hydrochloride, the TLC plate must be re-eluted with $0,5 \%$ ninhydrin solution in aquabidest, and then heated at $105^{\circ} \mathrm{C}$ for 15 min. Quantitative evaluation was performed by measuring the absorbance-reflectance of the analyte spot at $279 \mathrm{~nm}$ and $505 \mathrm{~nm}$ for Theophylline and Ephedrine hydrochloride, respectively. validation of the method show that TLC Densitometryis selective and specific,showed a good linearity, precise, and accurate and can be used for routine analysis of tablet in industrial quality control laboratories.

Keywords: TLC Densitometry, Validation, Theophylline, Ephedrine hydrochloride

\section{PENDAHULUAN}

Teofilin adalah obat asma yang cukup banyak digunakan dan mempunyai lingkup terapi sempit, yaitu jarak antara dosis terapi dengan dosis toksis sangat dekat. Obat ini sering digunakan dalam bentuk kombinasi dengan Efedrin hidroklorida. Teofilin digunakan untuk mengatasi obstruksi saluran nafas. Teofilin menimbulkan efek aditif bila digunakan bersama agonis beta-2 seperti Efedrin hidroklorida dosis kecil, sehingga kombinasi kedua obat tersebut dapat pula memperbesar kemungkinan efek samping termasuk hipokalemia dan peningkatan toksisitas Teofilin $^{(1)}$. Oleh karena itu, perlu adanya suatu jaminan mutu dari kedua obat tersebut baik secara kualitatif maupun kuantitatif.

Uji penetapan kadar Teofilin dan Efedrin hidroklorida secara simultan dalam sediaan farmasi masih belum terdapat dalam buku acuan resmi dan belum memiliki metode penetapan kadar yang terpublikasi, sehingga perlu dibuat metode analisis Teofilin dan Efedrin hidroklorida secara simultan dalam sediaan farmasi. Pada USP edisi 30 (2007) menyebutkan bahwa identifikasi bahan obat dalam sediaan tablet dengan tiga komponen yaitu Teofilin, 
Efedrin hidroklorida, dan Fenobarbital dapat dilakukan secara Kromatografi Lapis Tipis. Penelitian sebelumnya, telah dilakukan analisis kadar campuran obat Teofilin dan Efedrin hidroklorida secara simultan menggunakan metode Kromatografi Cair Kinerja Tinggi ${ }^{(2)}$, sedangkan untuk analisis kadar campuran obat dengan metode KLT Densitometri belum memiliki metode penetapan kadar yang terpublikasi. Oleh karena itu, pada penelitian ini akan dikembangkan suatu metode KLT Densitometri untuk penetapan kadar Teofilin dan Efedrin hidroklorida secara simultan.

Metode KLT Densitometri ini memiliki beberapa kelebihan yaitu spesifisitas yang tinggi, dapat dipercaya, pengerjaan relatif mudah dan cepat, biaya pengoperasian relatif murah, polaritas pelarut atau pelarut campuran dapat diubah dalam waktu singkat dan jumlah pelarut yang digunakan sedikit ${ }^{(3)}$. Selain itu, silika gel sebagai fase diam Kromatografi Lapis Tipis (KLT) juga dapat di daur ulang ${ }^{(4)}$. Jika dibandingkan dengan metode KCKT, metode KLT memiliki kelebihan yaitu pelaksanaannya lebih mudah dan lebih murah, serta peralatan yang digunakan lebih sederhana. Selain itu, metode KLT memberikan fleksibilitas yang lebih besar dalam hal memilih fase gerak, mempunyai berbagai macam teknik untuk optimasi pemisahan, proses kromatografi dapat diikuti dengan mudah, dan semua komponen dalam sampel dapat dideteksi karena metode ini memungkinkan terjadinya pemisahan sampel secara serentak ${ }^{(3)}$ Kelebihan yang lain ialah proses deteksi KCKT bersifat dinamis, sedang KLT lebih statis. Selain itu pada sistem KLT lebih mudah untuk mengubah atau menambah eluen agar sensitivitas dan selektivitasnya bertambah tanpa dibatasi waktu yang biasanya sangat berperan dalam sistem deteksi dinamis seperti $\mathrm{KCKT}^{(5)}$.

\section{BAHAN DAN METODA}

\section{Bahan}

Bahan-bahan yang digunakan adalah lempeng KLT Silika Gel 60 F254ukuran 20 x 20 $\mathrm{cm}$, kertas saring, standar Teofilin (Jilin Shulan Synthetic Pharmaceutical), standar Efedrin hidroklorida (Mongolia Ertok Qianqi Fupin Ephedrine Factory), Ninhidrin p.a, etanol 70\%, etil asetat p.a, asam asetat glasial, aquabides, sampel tablet Neo Napacin (Konimex) yang mengandung Teofilin $130 \mathrm{mg} /$ tablet dan Efedrin hidroklorida $12,5 \mathrm{mg} /$ tablet dan Asthma Soho (Soho)yang mengandung Teofilin $125 \mathrm{mg} /$ tablet dan Efedrin hidroklorida $12,5 \mathrm{mg} /$ tablet.

\section{Peralatan}

Alat-alat yang digunakan adalah labu ukur (10
$\mathrm{mL}, 25 \mathrm{~mL}, 50 \mathrm{~mL}$, dan $100 \mathrm{~mL}$ ) pyrex dan herma, erlenmeyer $100 \mathrm{~mL}$ pyrex, timbangan analitik Sartorius, pipet volume $(0,5 \mathrm{~mL}, 1 \mathrm{~mL}, 2 \mathrm{~mL}, 3 \mathrm{~mL}, 4 \mathrm{~mL}$, dan 5 $\mathrm{mL}$ ) pyrex, bola pipet, batang pengaduk, pipet tetes, mikropipet, vial, pipet ukur ( $1 \mathrm{~mL}, 5 \mathrm{~mL}, 10 \mathrm{~mL})$ pyrex, gelas ukur $25 \mathrm{~mL}$ pyrex, bejana camag (chamber), scanner Densitometer winCATS Camag, perangkat komputer dengan program winCATS ${ }^{()}$dan program Validation Method of Analysis (7), ultrasonic cleaner, pengering, dan lampu Ultra violet (UV).

\section{Metoda}

\section{Optimasi Kondisi Analisis}

\section{Optimasi Pelarut}

Optimasi pelarut dilakukan pemilihan pelarut dengan komposisi Kloroform : Metanol $\left(4: 1^{v} / \mathrm{v}\right)$ danEtanol $70 \%$, pelarut yang dipilih adalah pelarut yang mampu melarutkan analit dengan sempurna dimana kelarutannya diamati secara visual.

\section{Optimasi Eluen}

Optimasi eluen dilakukanpemilihan eluen dengan komposisi Etil Asetat p.a : Asam Asetat Glasial : Aquabides $=5: 5: 1(\mathrm{v} / \mathrm{v} / \mathrm{v})$; Etil Asetat p.a:Asam Asetat Glasial : Aquabides $=5: 5: 2(\mathrm{v} / \mathrm{v} / \mathrm{v})$; Etil Asetat p.a : Asam Asetat Glasial : Aquabides = 8:5:1(v/v/v); Etil Asetat p.a: Asam Asetat Glasial : aquabides $=11: 5: 1$ $(\mathrm{v} / \mathrm{v} / \mathrm{v})$. Penilaian eluen yang paling optimum berdasarkan parameter efisiensi kromatogram yaitu nilai $\mathrm{Rf}$ (Retardation factor) antara $0,20-0,80$, nilai $\mathrm{N}$ (Theoretical Plate Number) yang paling besar, nilai $\mathrm{H}$ (Height Equivalent to $A$ Theoretical Plate) yang terkecil, dan nilai Rs (Resolusi) $\geq 1,5.32$

\section{Optimasi Waktu Pengovenan}

Optimasi waktu pengovenan sebelum lempeng diwarna dengan larutan ninhidrin dilakukan dengan lama waktu 10 menit; 15 menit; 20 menit; 25 menit. Penilaian waktu pengovenan berdasarkan efisiensi waktu dan efisiensi kromatogram (dilihat dari baseline display kromatogram yang dihasilkan).

\section{Optimasi Teknik Pewarnaan}

Optimasi teknik pewarnaan lempeng dengan larutan ninhidrin untuk identifikasi Efedrin hidroklorida dilakukan dengan beberapa teknik pewarnaan yaitu dengan caradicelup dan dieluasi (diimpregnasi). Penilaian teknik pewarnaan lempeng dengan larutan ninhidrin didasarkan pada efisiensi kromatogram (dilihat dari baseline display kromatogram yang dihasilkan)

\section{Optimasi Panjang Gelombang $(\lambda)$}

Optimasi panjang gelombang dilakukan dengan scanning noda analit pada Camag TLC Scanner 
(Densitometer) dan software program winCATS ${ }^{()}$. Penilaian panjang gelombang optimum dengan melihat spektrum analit yang terbaca pada panjang gelombang maksimal pada area panjang gelombang $200-400 \mathrm{~nm}$ untuk Teofilin dan 400-800 $\mathrm{nm}$ untuk Efedrin hidroklorida.

\section{Validasi Metode Analisis}

\section{Uji Spesifisitas/Selektivitas}

Dibuat larutan standar Teofilin dan Efedrin hidroklorida dalam etanol $70 \%$ dengan konsentrasi masing-masing $5000 \mathrm{ppm}$ dan $500 \mathrm{ppm}$. Larutan sampel dibuat dengan cara menimbang $116 \mathrm{mg}$ sampel tablet Neo Napacin yang sudah digerus kemudian dilarutkan dengan etanol $70 \%$ dalam labu ukur $10 \mathrm{~mL}$ sehingga larutan mengandung Teofilin dan Efedrin hidroklorida dengan konsentrasi masing-masing 5000 ppm dan $480,8 \mathrm{ppm}$. Setelah itu larutan standar dan sampel ditotolkan pada lempeng KLT Silika Gel F254 masingmasing $2 \mu \mathrm{L}$ dengan mikropipet dimana masing masing larutan di replikasi kemudian dieluasi dan noda Teofilin yang terbentuk discanning pada panjang gelombang $279 \mathrm{~nm}$. Kromatogram Teofilin yang terbentuk diamati dan dicek korelasi spektra purity dan identity puncak standar dan sampel. Setelah noda Teofilin discanning, lempeng KLT dipanaskan pada oven suhu $105^{\circ} \mathrm{C}$ selama 15 menit, kemudian dilakukan pewarnaan pada lempeng dengan cara lempeng KLT dieluasi kembali dengan larutan ninhidrin $0,5 \%$ dalam aquabides. Setelah itu, lempeng dipanaskan pada oven suhu $105^{\circ} \mathrm{C}$ selama 15 menit, kemudian noda Efedrin hidroklorida yang terbentuk discanning pada panjang gelombang $505 \mathrm{~nm}$. Kromatogram Efedrin hidroklorida yang terbentuk diamati dan dicek korelasi spektra purity dan identity puncak standar dan sampel. Pada kromatogram sampel, dihitung Resolusi puncak Teofilin dan Efedrin hidroklorida terhadap puncak yang lain (unknown). Syarat: Nilai Resolusi (Rs) $\geq 1,5^{(8)}$.

\section{Uji Linieritas}

Dibuat larutan standar Teofilin dan Efedrin hidroklorida dalam etanol $70 \%$, dengan konsentrasi antara $4000 \mathrm{ng} /$ spot sampai $20.000 \mathrm{ng} / \mathrm{spot}$ dan 400 $\mathrm{ng} /$ spot sampai dengan $1.600 \mathrm{ng} / \mathrm{spot}$ masing-masing untuk teofilin dan efedrin hidroklorida. Setelah itu, larutan standar yang telah dibuat ditotolkan pada lempeng KLT Silika Gel F254 masing-masing $2 \mu \mathrm{L}$ kemudian dieluasi sampai tanda batas. Lempeng KLT kemudian dikeringkan dengan pengering dan noda Teofilin yang terbentuk discanning pada $\lambda 279 \mathrm{~nm}$. Kemudian dilakukan pewarnaan pada lempeng KLT untuk memvisualisasikan noda Efedrin hidroklorida, noda yang terbentuk discanning pada $\lambda 505 \mathrm{~nm}$ kemudian dihitung nilai parameter linieritas.

\section{Uji Batas Deteksi (LOD) dan Batas Kuantitasi (LOQ)}

Dibuat larutan standar Teofilin dalam etanol 70\% dengan konsentrasi150,6ppm; 205ppm; 301,2ppm; 410ppm; 502ppm dan larutan standar Efedrin hidroklorida dalam etanol $70 \%$ dengan konsentrasi 100,8ppm; 151,2ppm; 201ppm; 402ppm; 504ppm. Masing - masing larutan standarditotolkan pada lempeng KLT Silika Gel F254 sebanyak $2 \mu \mathrm{L}$, dieluasi dan noda Teofilin yang terbentuk discanning pada panjang gelombang $279 \mathrm{~nm}$. Setelah itu dilakukan pewarnaan pada lempeng KLT untuk menampakkan noda Efedrin hidroklorida, kemudian noda discanning pada $\lambda 505 \mathrm{~nm}$ dan dihitung nilai LOD dan LOQdari data hasil scanning dengan program Validation method of Analysis (7).

\section{Uji Keseksamaan (Precision)}

Dibuat larutan standar Teofilin dan Efedrin hidroklorida dalam etanol $70 \%$ sebanyak 6 konsentrasi terpilih berdasarkan hasil uji linieritas. Dibuat larutan sampel dengan konsentrasi Teofilin 5000ppm dan Ephedrin $\mathrm{HCl}$ 480,8ppmmasing - masing sebanyak 6 kali replikasi. Setelah itu larutan standar dan sampel ditotolkan pada lempeng KLT Silika Gel F254 masingmasing $2 \mu \mathrm{L}$ dengan mikropipet kemudian lempeng KLT dieluasi, noda Teofilin yang terbentuk discanning pada panjang gelombang $279 \mathrm{~nm}$. Setelah itu dilakukan pewarnaan pada lempeng KLT untuk menampakkan noda Efedrin hidroklorida, kemudian noda yang terbentuk discanning pada panjang gelombang $505 \mathrm{~nm}$. Prosedur diatas dilakukan sebanyak dua kali pada dua hari yang berbeda untuk menentukan intermediet precision (presisi antara) kemudian ditentukan nilai RSD-nya.

\section{Uji Keakuratan (Accuracy)}

Dibuat sampel adisi sediaan obat pada no. batch tertentu dengan penambahan bahan aktif (standar Teofilin dan Efedrin hidroklorida) sebanyak 30\%, 45\% dan $60 \%$ dari konsentrasi yang didapat dari hasil uji presisi masing-masing sampel adisi direplikasi $3 \mathrm{x}$. Larutan standar dan sampel ditotolkan pada lempeng KLT Silika Gel F254 masing-masing $2 \mu \mathrm{L}$ kemudian dieluasi sampai tanda batas. Noda Teofilin yang terbentuk discanning pada panjang gelombang $279 \mathrm{~nm}$ 
kemudian, dilakukan pewarnaan lempeng KLT untuk menampakkan noda Efedrin hidroklorida, kemudian discanning pada $\lambda 505 \mathrm{~nm}$ selanjutnya ditentukan \% recovery-nya.

\section{Penetapan Kadar Teofilin dan Efedrin HCl dalam Sampel Tablet}

Dibuat larutan standar Teofilin dan Efedrin hidroklorida dalam etanol $70 \%$ sebanyak 6 konsentrasi terpilih berdasarkan hasil uji linieritas. Pada penelitian ini sampel tablet yang digunakan adalah Neo Napacin (mengandung $130 \mathrm{mg}$ Teofilin dan 12,5 mg Efedrin $\mathrm{HCl}$ ) dan Asthma Soho (mengandung $125 \mathrm{mg}$ Teofilin dan 12,5 mg Efedrin $\mathrm{HCl}$ ). Dibuat larutan sampel dalam etanol $70 \%$ hingga didapatkan larutan sampel dengan konsentrasi \pm 5000 dan $500 \mathrm{ppm}$. Setelah itu, larutan standar dan sampel ditotolkan pada lempeng KLT Silika Gel F254 masing-masing $2 \mu \mathrm{L}$, lempeng dieluasi noda Teofilin discanning pada $\lambda 279$, kemudian dilakukan pewarnaan pada lempeng, noda Efedrin hidroklorida yang terbentuk discanning pada panjang gelombang $505 \mathrm{~nm}$.Dihitung kadar \% b/b (\% recovery kadar hasil percobaan terhadap kadar teoritis)

\section{HASIL DAN PEMBAHASAN}

\section{Optimasi Kondisi Analisis}

Berdasarkan hasil optimasi pelarut maka pelarut terpilih berdasarkan efektivitas dan efisiensi pelarutan adalah etanol $70 \%$. Sistem eluen yang terpilih berdasarkan hasil optimasi adalah eluen dengan komposisi etil asetat p.a. : asam asetat glasial : aquabides $(11: 5: 1 \mathrm{v} / \mathrm{v} / \mathrm{v})$ dengan nilai $\mathrm{Rf}$ Efedrin hidroklorida dan Teofilin sebesar 0,69 dan 0,33, nilai $\mathrm{N}$ $=451$ dan 89 serta nilai $\mathrm{H}=0,02$ dan 0,10 dengan lama penjenuhan dan eluasi selama \pm 30 menit. Waktu pengovenan yang dipilih sesuai hasil optimasi adalah 15 menit, karena bentuk kromatogram yang dihasilkan lebih simetris dibandingkan dengan kromatogram yang lain. Selain itu, baseline display kromatogram yang dihasilkan dengan waktu pengovenan 15 menit juga lebih rendah dibandingkan dengan kromatogram yang lain sehingga lebih mudah dalam pengintegrasian area peak (Gambar 1).Teknik pewarnaan terpilih sesuai hasil optimasi adalah dengan teknik eluasi karena dapat menghasilkan kromatogram dengan baseline display antara sisi kanan dan sisi kiri kromatogram yang sama/sejajar sehingga integrasi area puncakmenjadi lebih jelas (Gambar 2). Panjang gelombang terpilih didasarkan pada hasil scanning spektra Teofillin danEfedrin hidroklorida dapat dilihat pada Gambar 3.

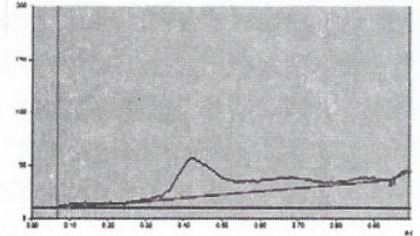

10 menit

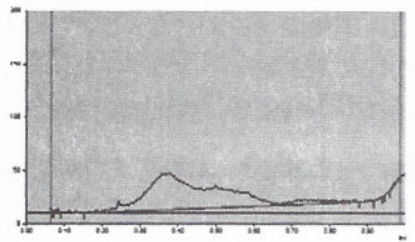

20 menit

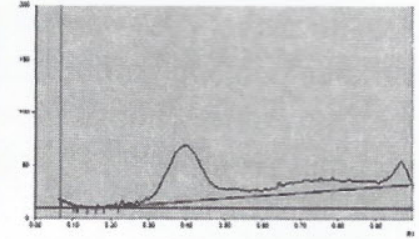

15 menit

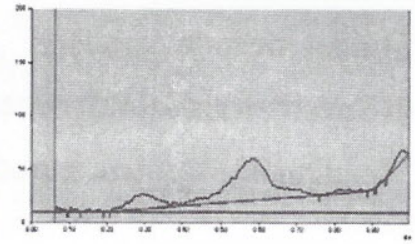

25 menit
Gambar 1. Hasil optimasi lama pengovenan

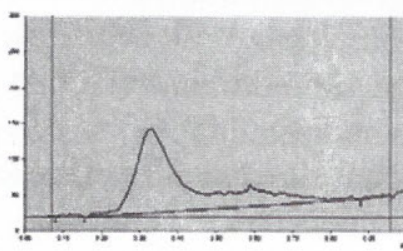

Cara dicelup

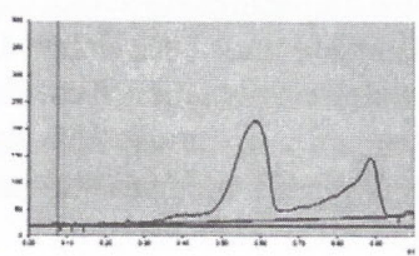

Cara dieluasi
Gambar 2. Hasil optimasi teknik pewarnaan

Berdasarkan spektra yang didapatkan diatas, dapat diketahui bahwa absorbansi maksimal tercapai pada saat panjang gelombang Teofilin $279 \mathrm{~nm}$ dengan nilai absorbansi sebesar 95,0 AU (Absorption Unit) dan panjang gelombang Efedrin hidroklorida adalah $505 \mathrm{~nm}$ dengan nilai absorbansi sebesar 94,9 AU. Dari keseluruhan optimasi yang dilakukan, didapatkan kondisi analisis yang optimum yang digunakan untuk analisis Teofilin dan Efedrin hidroklorida secara simultan sesuai yang tercantum pada Tabel 1 .
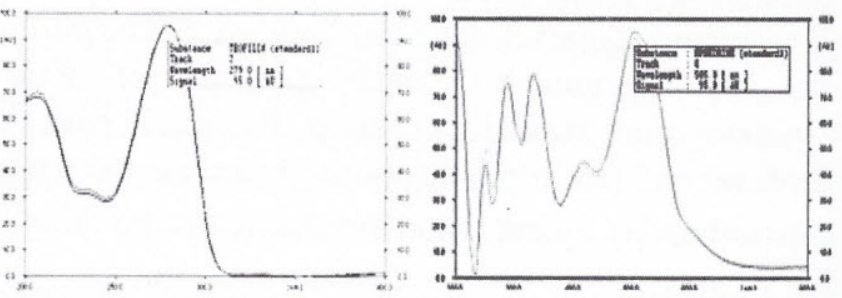

Gambar 3. (a) Spektra Teofilin pada panjang gelombang 200-400 nm (b) Spektra Efedrin hidroklorida pada panjang gelombang $200-800 \mathrm{~nm}$

Tabel 1. Kondisi Analisis Teofilin dan Efedrin Hidroklorida

\begin{tabular}{cll}
\hline No & Kondisis Analisis & Hasil Optimasi \\
\hline 1. & Pelarut & Etanol 70\% \\
\hline 2. & Eluen & Etil asetat p.a. : Asam asetat glasial : aquabides = 11:5:1 \\
\hline 3. & Lama waktu pengovenan & 15 menit \\
\hline 4. & Teknik pewarnaan lempeng & Dieluasi \\
\hline 5. & Panjang gelombang & Teofilin $279 \mathrm{~nm} ;$ Efedrin $\mathrm{HCl} 505 \mathrm{~nm}$ \\
\hline 6. & Konsentrasi uji & Teofilin $5000 \mathrm{ppm}$, Efedrin $\mathrm{HCl} 500 \mathrm{ppm}$ \\
\hline
\end{tabular}


memenuhi syarat penerimaan uji presisi. Nilai RSD uji presisi repeatability Teofilin 1,707\% dengan mean recovery $101,8 \%$ dan rata-rata RSD pada presisi antara $1,953 \%$ dengan mean recovery $102,7 \%$. Nilai RSD dan mean recovery yang didapatkan telah memenuhi syarat penerimaan uji presisi untuk Teofilin. Nilai RSD uji presisi repeatability untuk Efedrin hidroklorida 2,838\% dengan mean recovery $97,36 \%$ dan rata-rata RSD pada uji presisi antara adalah 1,945\% dengan mean recovery 98,98\%. Nilai RSD dan mean recovery tersebut telah memenuhi syarat penerimaan uji presisi untuk Efedrin hidroklorida.

\section{Akurasi (Kecermatan)}

Akurasi menunjukkan derajat kedekatan hasil analisis dengan kadar analit yang sebenarnya, yang ditentukan berdasarkan nilai \% recovery (perolehan kembali) analit yang didapatkan. Uji akurasi dilakukan dengan menghitung \% recovery yang dihasilkan dari penambahan standar obat sebanyak $30 \%, 45 \%$, dan $60 \%$ dari kadar analit dalam sampel yang didapat dari hasil uji presisi ${ }^{(12)}$. Hasil uji akurasi Teofilin dapat dilihat pada tabel 3 sedangkan hasil uji akurasi Efedrin hidroklorida dapat dilihat pada tabel 4. Berdasarkan data pada tabel 4. dapat diketahui bahwa untuk senyawa Teofilin dihasilkan $\%$ Recovery $\pm \% \mathrm{RSD}=100,7 \% \pm 1,953 \%$ dan $\%$ Recovery $\pm \%$ RSD untuk Efedrin hidroklorida sebesar $98,23 \% \pm 2,054 \%$. Nilai tersebut memenuhi persyaratan uji akurasi Efedrin hidroklorida.

Tabel 3. Hasil Pengujian Akurasi Senyawa Teofilin

\begin{tabular}{|c|c|c|c|c|c|}
\hline $\begin{array}{l}\text { Penambahan } \\
\text { Standar }\end{array}$ & $\begin{array}{l}\text { Penimbangan } \\
\text { Sampel Adisi }\end{array}$ & $\begin{array}{c}\text { Konsentrasi } \\
\text { Teoritis } \\
\text { (ng/spot) }\end{array}$ & $\begin{array}{l}\text { Konsentrasi } \\
\text { Percobaan } \\
\text { (ng/spot) }\end{array}$ & $\begin{array}{c}\text { Recovery } \\
(\%)\end{array}$ & $\begin{array}{l}\text { RSD } \\
(\%)\end{array}$ \\
\hline \multirow{3}{*}{$30 \%$} & 116,2 & 11688 & 11520 & 98,56 & \multirow{3}{*}{1,047} \\
\hline & 116,1 & 11678 & 11670 & 99,93 & \\
\hline & 116,2 & 11688 & 11760 & 100,6 & \\
\hline \multirow{3}{*}{$45 \%$} & 116,2 & 12260 & 12230 & 99,76 & \multirow{3}{*}{3,052} \\
\hline & 116,4 & 12280 & 12640 & 102,9 & \\
\hline & 116,4 & 12280 & 11900 & 96,91 & \\
\hline \multirow{3}{*}{$60 \%$} & 116,2 & 12766 & 13270 & 103,9 & \multirow{3}{*}{1,761} \\
\hline & 116,1 & 12754 & 12810 & 100,4 & \\
\hline & 116,1 & 12754 & 13130 & 102,9 & \\
\hline \multicolumn{4}{|c|}{ Rata-rata } & $100,7 \%$ & $1,953 \%$ \\
\hline
\end{tabular}

Tabel 4. Hasil Pengujian Akurasi Efedrin Hidroklorida

\begin{tabular}{|c|c|c|c|c|c|}
\hline $\begin{array}{c}\text { Penambahan } \\
\text { Standar }\end{array}$ & $\begin{array}{l}\text { Penimbangan } \\
\text { Sampel Adisi }\end{array}$ & $\begin{array}{c}\text { Konsentrasi } \\
\text { Teoritis } \\
\text { (ng/spot) }\end{array}$ & $\begin{array}{c}\text { Konsentrasi } \\
\text { Percobaan } \\
\text { (ng/spot) }\end{array}$ & $\begin{array}{c}\text { Recovery } \\
(\%)\end{array}$ & $\begin{array}{l}\text { RSD } \\
(\%)\end{array}$ \\
\hline \multirow{3}{*}{$30 \%$} & 116,2 & 1083 & 1068 & 98,61 & \multirow{3}{*}{2,903} \\
\hline & 116,1 & 1082 & 1008 & 93,16 & \\
\hline & 116,2 & 1083 & 1050 & 96,95 & \\
\hline \multirow{3}{*}{$45 \%$} & 116,2 & 1136 & 1141 & 100,4 & \multirow{3}{*}{1,261} \\
\hline & 116,4 & 1138 & 1158 & 101,8 & \\
\hline & 116,4 & 1138 & 1130 & 99,30 & \\
\hline \multirow{3}{*}{$60 \%$} & 116,2 & 1183,8 & 1186 & 100,2 & \multirow{3}{*}{1,997} \\
\hline & 116,1 & 1182,8 & 1144 & 96,72 & \\
\hline & 116,1 & 1182,8 & 1147 & 96,97 & \\
\hline \multicolumn{4}{|c|}{ Rata-rata } & $98,23 \%$ & $2,054 \%$ \\
\hline
\end{tabular}

\section{Penetapan Kadar Teofilin dan Efedrin Hidroklorida dalam Sampel Tablet}

Tahap terakhir dari penelitian ini setelah metode analisis yang dikembangkan dinyatakan valid adalah melakukan penerapan metode analisis yang dikembangkan, yaitu melakukan penetapan kadar Teofilin dan Efedrin hidroklorida dalam sediaan tablet secara KLT densitometri. Pada penelitian ini, sampel obat yang digunakan adalah Neo Napacin (Konimex) dan Asthma Soho (Soho) yang diperoleh dari apotek di sekitar Universitas Jember. Hasil penetapan kadar Teofilin dan Efedrin hidroklorida pada kedua sampel tersebut dapat dilihat pada Tabel 5.

Tabel 5. Hasil Penetapan Kadar Teofilin dan Efedrin Hidroklorida

\begin{tabular}{llc}
\hline Nama Sampel & \multicolumn{1}{c}{ Bahan Aktif } & \% Mean Recovery * ${ }^{R S D}$ \\
\hline Neo Napacin & Teofilin & $102,5 \% \pm 3,349 \%$ \\
& Efedrin Hidroklorida & $100,8 \% \pm 3,767 \%$ \\
\hline Asthma Soho & Teofilin & $104,3 \% \pm 0,484 \%$ \\
& Efedrin Hidroklorida & $103,5 \% \pm 3,997 \%$ \\
\hline
\end{tabular}

* \% Mean Recovery merupakan rata-rata perbandingan kadar hasil percobaan dengan konsentrasi teoritis dalam label/etiket

Dalam monografi buku acuan standar dinyatakan bahwa persyaratan kadar Teofilin dalam sediaan tablet bila dibandingkan label claimadalah $94-106 \%{ }^{(13)}$, sedangkan untuk Efedrin hidroklorida dalam sediaan tablet adalah $92,5-107,5 \%{ }^{(14)}$. Dari data yang diperoleh, maka dapat disimpulkan bahwa kadar Teofilin dan Efedrin hidroklorida dalam sampel tablet Neo Napacin dan Asthma Soho telah memenuhi rentang kadar yang dipersyaratkan dalam monografi.

\section{KESIMPULAN}

Metode KLT Densitometri untuk analisis Teofilin dan Efedrin hidroklorida secara simultan dalam sampel tablet memberikan hasil analisis yang selektif, spesifik, linier, peka, presis dan akurat. kadar rata-rata pada tablet Neo Napacin adalah Teofilin sebesar 102,5\% dan Efedrin hidroklorida sebesar 100,8\%, sedangkan pada tablet Asma Soho didapatkan kadar rata-rata Teofilin sebesar 104,3\% dan Efedrin hidroklorida sebesar $103,5 \%$ dengan tingkat kepercayaan untuk teofilin $100,7 \%$ dan untuk ephedrin $98,2 \%$.

\section{DAFTAR PUSTAKA}

1. T. H.Tjay, \&K.Rahardja, 2007. Obat-Obat Penting Khasiat, Penggunaan dan Efek-Efek Sampingnya EDISI 6. Jakarta : PT Gramedia. Pratiwi, P. Skripsi. Fakultas Farmasi Universitas 
Sumatera Utara. 2011 [serial online] http://repository.usu.ac.id/bitstream/123456789/ 22856/6/Abstract.pdf[15 April 2012].

2. P. Pratiwi, Skripsi. Fakultas Farmasi Universitas Sumatera Utara. 2011 [serial online] http://repository.usu.ac.id/bitstream/123456789/ 22856/6/Abstract.pdf[15 April 2012].

3. A. Rohman. 2009. Kromatografi untuk Analisis Obat. Edisi Pertama. Yogyakarta: Graha Ilmu.

4. L. Wulandari. 2006. Evaluation of Re-Used HPTLC Plate for Qualitative and Quantitative Analysis, Indonesian Journal of Chemistry, Vol. 6 No.3

5. Kurnia, Yasavati. 1990. Penetapan Kadar Ketoprofen Serum dengan Cara Kromatografi Lapis Tipis Densitometri. [serial online] http://www.ukrida.ac.id/jkunukr/proc/fkedd/199 2/jkunukr-ns-proc-1992-2020-1506-ketoprofenresource.pdf[10 Mei 2012]75

6. CAMAG. 2012. Basic Equipment for Modern Thin-Layer Chromatography. Switzerland : CAMAG. [serial online]. http://www.camag.com /downloads/free/brochures/CAMAG-basicequipment-08.pdf[24April 2012]

7. A. Indrayanto, G. Indrayanto dan M. Mulya. 2003. Validation Method of Analysis v1.03. Software from General Public Licence. Faculty of Pharmacy. Surabaya:Airlangga University.
8. Harmita. 2004. Petunjuk Pelaksanaan Validasi Metode dan Cara Perhitungannya. Majalah Ilmu Kefarmasian.Vol. I, no.3, 117 - 135. Desember 2004. Jakarta : Universitas Indonesia Press. [serial online] http://jurnal.farmasi.ui.ac.id/pdf /2004/v01n03/Harmita010301.pdf [23 April 2012].

9. L. Wulandari, G. Indrayanto. 2003. Densitometric Determination of Betamethasone Dipropionate and Salisylic Acid in Lotion, and Its Validation. Journal of Planar Chromatography. Vol 16.

10. J.Ermer. and J.Miller.2005. Method Validation in Pharmaceutical Analysis.AGuide to Best Practice, WILEY-VCH Verlag GmbH \& Co. KGaA, Weinheim

11. L. Huber. 2007. Validation and Qualification in Analytical Laboratories. 2nd edition. New York: Informa Healthcare USA, Inc.

12. G. Indrayanto, dan M.Yuwono. 2003. Validation of TLC Analysis. Encyclopedia of Chromatography. Marcel Dekker, Inc

13. United State Pharmacopoeial Convention. 2007. The United State Pharmacopoeia 30-National Formulary 25. Asia Edition. Rockville: United State Pharmacopoeial Convention.

14. Depkes RI. 1995. Farmakope Indonesia Edisi IV. Departemen Kesehatan Republik Indonesia : Jakarta 